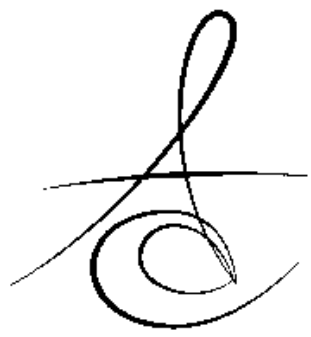

\title{
DİŞ HEKİMLİĞİNDE ADEZYON VE ADEZİV REZİN SİMANLARDA GÜNCEL YAKLAŞIMLAR
}

\section{ADHESION IN DENTISTRY AND NEW APPROACHES OF ADHESIVE RESIN CEMENTS}

\author{
Dr. Sibel DİKİCİER *
}

Makale Kodu/Article code: 2311

Makale Gönderilme tarihi: 16.06 .2015

Kabul Tarihi: 09.07.2015

öz

Sabit protetik restorasyonların başarısını etkileyen esas faktörlerden biri, restorasyonun dişe tutunmasını sağlayan simantasyon işlemidir. Son 15-20 yıldır; konvansiyonel simanlara oranla daha az mikrosızıntı ve uzun klinik ömre sahip olduğu için metal desteksiz porselen restorasyonların, laminate veneerlerin, inley ve onleylerin, adeziv köprülerin simantasyonunda adeziv rezin simanlar tercih edilmektedir. Basma ve çekme dayanıklılıklarının diğer simanlara göre daha iyi olması rezin simanların en büyük avantajıdır. Elastisite modülü çinko fosfat simanlardan daha düşük, fakat kırılmaya karşı dayanıklılık ve sertliği daha fazladır. Rezin simanlardaki mikro doldurucular; viskozite, film kalınlığı ve aşınmaya karşı direnci de arttırır. Bu derlemenin amacl; dişhekimliğinde adezyon kavramı, adeziv rezin simanların kullanımı, klinik prosedürleri ve güncel gelişimini değerlendirmektir.

Anahtar kelimeler: dental adezyon, dental bonding, rezin siman

\section{GİRİş}

Sabit protezlerin klinik başarısında simantasyonun önemli bir rolü vardır. Diş preparasyonunda rezistans ve retansiyon formları her ne kadar başlıca öneme sahip olsa da; dental siman, mikrobiyal sızıntıya karşı bir bariyer görevi yapmalı, diş ve restorasyon arasında bağlantı oluşturmalı ve yüzey bağlantılarıyla ikisini bir arada tutmalıdır. Bu bağlantı mekanik, kimyasal veya her ikisinin kombinasyonu şeklinde olabilir. ${ }^{1}$ Adeziv rezin simanlar için ilk adımlar 1962 yılında Bowen tarafından BİS-GMA' nın (bisfenol A-glisidil

\section{ABSTRACT}

One of the main factors affecting the success of the fixed prosthetic restorations, is a cementation process to hold the restoration on teeth. The last 15-20 years; adhesive resin cements have preferred in cementation of all-ceramics, laminate veneers, inlay-onlay restorations and adhesive bridges, because of the long clinical performance and less microleakage compared to conventional cements. Compression and tensile strength of the resin cements are greater than the other cements. Their elasticity modulus are lower than that of zinc phosphate cement, but greater fracture resistance and toughness. Micro fillers in resin cements also increases viscosity, film thickness and the resistance to abrasion. The objective of this review was to evaluate dental adhesion, the clinical procedures of adhesive resin cements and their current development.

Keywords: dental adhesion, dental bonding, resin cement

metakrilat) bulunması ile atılmıştır. Bunun sonucu olarak da 1963 yılında ilk büyük dolduruculu dolgu materyallerinin kullanılmasıyla geliştirilmiştir. ${ }^{2-4}$ İlk bulunduğu yıllarda pulpa hasarı oluşturabileceği düşüncesi, aşınma dirençlerinin yetersiz oluşu, radyolusent olmaları, kenar uyumsuzlukları ve akışkan kıvamları nedeniyle kullanımları sınırlanmıştır. Ancak adeziv teknolojisindeki gelişmeler neticesinde; geleneksel simanlarla kıyaslandığında dentine bağlantı kuvvetlerinin arttırılması, materyalin doldurucu oranı ve kimyasal katkı oranları gibi özelliklerinin geliştirilmesi sonucunda günümüzde klinik kullanımları çok yaygındır. ${ }^{3,5}$

* Çorlu Asker Hastanesi, Diş Servisi, Tekirdağ 


\section{Dental adezyon ve adeziv sistemlerin gelişimi}

Adezyon, farklı moleküller arasındaki çekim kuvvetidir. Dişhekimliğinde adezyon; dental adezyon veya dental bonding olarak isimlendirilir. Yüzey enerjisi yüksek olan maddeler hidrofilik, düşük olanlar ise hidrofobik özellik sergilerler. Diş yüzeyinde plak, diştaşı, tükürük, kan, enzimatik bileşikler ve yiyecek artıkları gibi eklentilerin bulunması, kurutma işleminde kullanılan havadaki nem ve yağ taneciklerinin varlığı, diş dokusunun yüzey gerilim değerini düşürür ve adezyonu olumsuz yönde etkiler. Ayrıca, pürüzlendirilmiş dentin ve adeziv rezin siman, hidrofobik karakterdedir. Bu yüzden iki yapı arasındaki adezyonu sağlamak amacıyla denting bonding sistemleri (adesiv sistemler) geliştirilmiştir. Dentin bonding sistemlerinde birincil eleman olan HEMA (hidroksietil metakrilat) ve 4-META (metakriloksi etil trimellitik anhidrat) gibi hidrofilik rezin monomer içeren primerler, dentinin yüzey enerjisini arttırırlar, adeziv rezinin dentin üzerine yayılabilmesini sağlarlar. ${ }^{6}$

Dentin bonding sistemler için yapılan çok çeşitli sınıflamalar vardır. Kimyasal yapılarına göre (oksalat, gluteraldehit HEMA, BİS-GMA, poliheksanit metakrilat, fosfonat dimetakrilat, sitrik asit), bağ dayanımlarına göre (5-7 MPa arası, 8-14 MPa arası, $17 \mathrm{MPa}$ 'dan yukarısı), asitleme özelliklerine göre (total-etch, selfetch) klinik uygulama şekillerine göre (tek, iki, üç aşamalı) ve üretim tarihlerine göre sınıflandırılabilirler.

En çok kullanılan sınıflamalar; klinik uygulama şekillerine (Tablo 1) ve üretim tarihlerine göre yapılan sınıflamalardır.

\section{Klinik uygulama şekillerine göre;}

- Tek Aşamalı Sistemler (tek şişe sistemler; allin-one): Self etch (kendinden asitli) sistemlerdir. Asit, primer ve bonding tek şişede birleştirilmiştir.

- İki Aşamalı Sistemler: Total-etch uygulaması yapılacaksa bu sistemlerde primer ve bonding birleştirilmiştir. Asit + bonding olarak iki aşamada uygulanır. Self etch'te ise, asit ve primer birleştirildiği için, primer + bonding olarak iki aşamada uygulanır.

- Üç Aşamalı Sistemler: Sadece total-etch uygulaması geçerlidir. Asit+primer+bonding 3 ayrı aşamada uygulanır. $^{7}$

\section{Üretim tarihlerine göre;}

1.nesil dentin bonding sistemler: 1960'lı yılların ortasında üretilen ve bağlanma gücü $3 \mathrm{MPa} d a n$ az olan ilk nesildir.
Tablo 1. Dentin bonding sistemleri

\begin{tabular}{|c|c|c|}
\hline & $\begin{array}{c}\text { TOTAL ETCH } \\
\text { (asit + bonding) }\end{array}$ & $\begin{array}{c}\text { SELF ETCH } \\
\text { (primer + bonding) }\end{array}$ \\
\hline $\begin{array}{l}\text { tek } \\
\text { aşamalı } \\
\text { sistemler } \\
\text { (all-in- } \\
\text { one) }\end{array}$ & & $\begin{array}{c}\text { Clearfil S3 Bond (KURARAY) } \\
\text { Futura Bond DC Single } \\
\text { Dose (VOCO) } \\
\text { Futurabond NR Single Dose (VOCO) } \\
\text { Admira Bond (VOCO) } \\
\text { Adper Prompt L Pop (3M ESPE) } \\
\text { Adper Easy One (3M ESPE) } \\
\text { Optibond All-in-one (KERR) } \\
\text { Xeno III (Dentsply) }\end{array}$ \\
\hline $\begin{array}{c}\text { iki } \\
\text { aşamalı } \\
\text { sistemler }\end{array}$ & $\begin{array}{c}\text { Clearfil Photo Bond } \\
\text { (KURARAY) } \\
\text { Clearfil New Bond } \\
\text { (KURARAY) } \\
\text { Solobond M (VOCO) } \\
\text { One Step Plus (BISSCO) } \\
\text { Adper Single Bond } 2 \\
\text { (3M ESPE) } \\
\text { Optibond Solo Plus } \\
\text { (KERR) } \\
\text { Prime \& Bond NT } \\
\text { (Dentsply) }\end{array}$ & $\begin{array}{l}\text { Clearfil SE Bond (KURARAY) } \\
\text { Clearfil Liner Bond (KURARAY) } \\
\text { Futura Bond DC (VOCO) } \\
\text { Futurabond NR (VOCO) } \\
\text { Adper SE Plus (3M ESPE) }\end{array}$ \\
\hline $\begin{array}{c}\text { üç } \\
\text { aşamalı } \\
\text { sistemler }\end{array}$ & $\begin{array}{l}\text { Solobond Plus (VOCO) } \\
\text { All Bond } 2 \text { (BISCO) } \\
\text { Adper Scotchbond } \\
\text { Multi Purpose } \\
\text { (3M ESPE) } \\
\text { Optibond FL (KERR) }\end{array}$ & \\
\hline
\end{tabular}

2.nesil dentin bonding sistemler: Yapılarına HEMA eklenerek bağlanma gücü 3 MPa'ya yükseltilen bu neslin ilk örneği 1978 yılında piyasaya sürülmüştür. ${ }^{8}$ Smear tabakasının altındaki dentine zayıf bağlanması yüzünden bu sistemlerin dentine bağlantısı sınırlı olmuştur. ${ }^{8,9}$ Ağız ortamında hidrolize olmaları ve dentin-sement marjinlerinde mikrosızıntıyı önleyememeleri diğer dezavantajlarıdır. ${ }^{8,10} \mathrm{Bu}$ nesile; Scotchbond (3M), Clearfil bond (KURARAY) sistemleri örnek verilebilir.

3.nesil dentin bonding sistemler: 1979 yılında tanıtılan bu nesil ise smear tabakasını kaldıran düzenleyiciler içermektedir ve bağlanma dayanımı 18 MPa'ya kadar ulaşmaktadır. ${ }^{8}$ Variolink II (IVOCLAR) bu nesil sistemlere örnektir.

4.nesil dentin bonding sistemler: 1984 yılında piyasaya sürülen bu nesilde smear tabakası fosforik asitle yıkanarak uzaklaştırılır. Bu grubu öncekilerden ayıran en önemli özellik, dentine bağlanmalarınn neredeyse mineye bağlanma kadar güçlü olması ve nemli dentine de güçlü bağlanabilmeleridir. ${ }^{8}$ Ayrıca metal ve porselen yüzeylere de bağlanabilme özelikleri vardır. Adeziv sistemlerin kompozit rezini metale bağlayabildiği birçok araştırıcı tarafından gösterilmiştir. ${ }^{11}$ All Bond 2 (BISCO), Panavia F (KURARAY) bu nesildedir.

5.nesil dentin bonding sistemler: Bu ürünler iki basamaklıdır; asitleme ve primerleme işlemlerini aynı anda yapabilen self-etch adezivler de beşinci nesil

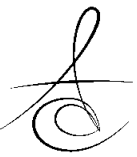


içerisinde anılır. ${ }^{8}$ Rely X ARC (3M), C\&B SuperBond (SUN MEDICAL), Adper Single Bond 2 (3M), One Step (BİSCO) beşinci nesil adeziv sistemlere örnektir.

6.nesil dentin bonding sistemler: Self etch all-inone olarak adlandırılan bu sistemlerde asit, primer ve bonding tek şişede birleştirilmiştir. ${ }^{12} \mathrm{Bu}$ sistemlere örnek olarak ise Rely X Unicem (3M), Adper Prompt LPop (3M) verilebilir.

7.nesil dentin bonding sistemler: 2002 yllında geliştirilmiş tek şişe son nesil sistemlerdir. Cam iyonomer bazlı olması ve bazı türlerinin flor salabilmesi gibi özellikler içerir. ${ }^{13,14}$ Adper Easy One (3M) bu nesilden bir bonding sistemidir.

\section{Adeziv rezin simanların kimyasal özellikleri}

Rezin simanlar asitle pürüzlendirilmiş mine ve dentine büyük oranda mikromekaniksel olarak, daha az oranda kimyasal bağların etkisiyle bağlanırlar. 4META (4-metakriloksietil trimellitat anhidrit) veya MDP (metakriloksi diketil fenil fosfat) monomeri içeren rezin simanlar metal yüzeyi üzerindeki oksit tabakasılyla meydana gelen kimyasal etkileşimleri sonucu da kuvvetli bir bağlantı kurarlar. ${ }^{15}$ Çoğu rezin siman ağırlıkça \% 50-70 oranında cam ve silika içerir. Bu doldurucular sayesinde yüksek basma dayanıklıı̆ına sahiptirler. Gerilim kopmasına karşı direnç gösterirler ve çözünürlükleri azalmıştır. ${ }^{2}$

Kompozit rezinler 3 komponentten meydana gelirler. Bu komponentler; organik polimer matriks faz (sürekli faz, continuous phase), inorganik faz (inorganik filler, dağılmış faz, dispersed phase) ve ara faz (bağlanma fazı, silan bağlama maddesi, silane coupling agent) olarak isimlendirilmiştir. ${ }^{2}$ Organik matriks içerisinde Bis-GMA, UDMA (üretan dimetakrilat) ve TEG-DMA (trietilenglikol-dimetakrilat) yer alırken; inorganik doldurucular matriks içine dağıtıımış çeşitli şekil ve büyüklükteki kuartz, borosilikat cam, lityum alüminyum silikat, stronsiyum, baryum, çinko ve yitriyumdan oluşurlar. ${ }^{16}$ UDMA, renk değişimine daha dirençli olup, iyi adezyon sağlar. Hem Bis-GMA hem de UDMA aşırı visköz yapıya sahip olduğundan visköziteyi azaltmak için matrikse TEG-DMA ilave edilmiştir. 2,17 Ara faz ise organik silisyum bileşiği olan silanlardan meydana gelir. ${ }^{3,4}$

\section{Adeziv Rezin Simanların Avantajları}

1- Fiziksel ve mekanik dayanıkııı̆ı fazladır.

2- Çözünürlüğü düşüktür.

3- Farklı maddelere bağlanabilme yeteneğine sahiptir.

4- Pek çok renk ve opasite seçeneklerine sahiptirler.
Renk stabiliteleri polimerizasyon derecelerine bağlıdır. Porselenin rengi, kalınlığı, opaklığı, yapıştııcı simanın polimerizasyon tipi, doldurucu içeriği, ışık cihazının tipi ve çıkış yoğunluğu gibi pek çok faktör adeziv rezin simanların polimerizasyonunu etkilemektedir. ${ }^{18}$

5- Adezyonu iyi olduğu için daha konservatif preparasyon şekillerine müsaade eder.

6- Seramiklerin altında kullanıldıklarında seramiğin kırıma direncini arttırırlar.

7- Bazı rezin simanların 'yiterbiyum triflorid' içeriklerine bağlı olarak flor salma özelliği vardır. ${ }^{1,19}$

\section{Adeziv Rezin Simanların Dezavantajları}

1- Pulpada hassasiyet: Post-operatif hassasiyeti azaltmak için dişin ıslanabilirliği ile bağlantı dayanıklığını arttırmak gereklidir. Bunun için en başarilı yöntem, self-etch primeri olan bir sistemin simantasyon öncesi kullanılmasıdır. Bu teknikte smear tabakası tamamen kaldırımayıp, kısmen eritilerek bağlantıya dahil edildiği için hassasiyetin önlenmesinde oldukça başarıııır. ${ }^{4}$ Bir başka yöntem de dişin asitle pürüzlendirilmesini takiben, hassasiyet giderici bir ajanın kullanılmasıdır.

2- Mikrosızıntı: İyi bir bağlantı sağlamak ve mikrosızıntıyı önlemek için diş yüzeyinin kontaminasyonuna engel olmak gerekir. ${ }^{20}$

3- Hassas manipülasyon: Siman sertleştikten sonra taşan simanın temizlenmesi zordur. Eğer siman sertleşmeden önce temizlenirse; restorasyon ile diş arasındaki marjinal bölgede açıklık kalmasına, post-op hassasiyete ve devamında da çürük oluşmasına neden olabilir. Bununla beraber simanın tamamen donmasına izin verilirse frez yardımı olmadan temizlenmesi hemen hemen imkansızdır. Bu yüzden restorasyon yerleştirildikten sonra; siman oksijen varlı̆ında polimerize olamadığından, hava ile temasını bloke eden ajanların (oxyguard, propylene-glikol) restorasyon kenarlarına yerleştirilmesi önerilmektedir. ${ }^{4,6}$

Adeziv rezin simanlar, polimerizasyon tiplerine göre 3 ana grupta incelenirler:

a) Kimyasal olarak polimerize olan (chemicalcure, self-cure) adeziv rezin simanlar

b) Işık ile polimerize olan (light-cure) adeziv rezin simanlar

c) Hem kimyasal olarak hem de ışı ile polimerize olan (dual-cure) adeziv rezin simanlar. ${ }^{2}$

(Tablo 2) 
Tablo 2. Kimyasal reaksiyon şekline göre rezin siman sistemleri

\begin{tabular}{|c|c|c|}
\hline $\begin{array}{c}\text { Kimyasal + Işık } \\
\text { (dual-cure) }\end{array}$ & $\begin{array}{c}\text { Kimyasal } \\
\text { (self-cure) }\end{array}$ & $\begin{array}{c}\text { Işık } \\
\text { (light-cure) }\end{array}$ \\
\hline $\begin{array}{c}\text { Variolink (IVOCLAR) } \\
\text { Panavia F (KURARA) } \\
\text { Clearfil Esthetic Cement } \\
\text { (KURARAY) } \\
\text { Resilute (PULPDENT) } \\
\text { Nexus } 3 \text { (KERR) } \\
\text { Relyx ArC (3M ESPE) } \\
\text { Calibra (DENTSPLY) } \\
\text { Duulink (BISCCO) } \\
\text { Illusion (BISSCO) } \\
\text { Relyx Unicem (3M ESPE)* } \\
\text { Relyx U 200 (3M ESPE)* } \\
\text { Maxcem (KERR)* } \\
\text { Panavia SA CEMENT PLUS } \\
\text { (KURARAY)* } \\
\text { Biscem (BISCO)* } \\
\text { Bifif SE (VOCO)* } \\
\text { Speed-CEM (IVOCLAR)* } \\
\text { SMART-CEM 2 (DENTSPLY)* } \\
\text { I-CEM (HERAEUS-KULZER)* }\end{array}$ & $\begin{array}{l}\text { Multilink (IVOCLAR) } \\
\text { Panavia 21 } \\
\text { (KURARAY) } \\
\text { Superbond C\&B } \\
\text { (MORITA) } \\
\text { C\&B Metabond } \\
\text { (SUN MEDICAL) } \\
\text { C\&B cement (BISCO) }\end{array}$ & $\begin{array}{l}\text { Relyx Veneer } \\
\text { (3M ESPE) } \\
\text { Compson QD } \\
\text { (DENTSPLY) } \\
\text { N×3 (KERR) } \\
\text { Choice (BISCO) }\end{array}$ \\
\hline
\end{tabular}

* Self-adeziv rezin simanlar

\section{a) Kimyasal olarak polimerize olan adeziv rezin simanlar (self-cure)}

Bu simanlar, çift pat sisteminde yada toz-likit şeklinde üretilmiştir. Polimerizasyon iki komponentin karıştırılması ile kimyasal yolla başlamaktadır. Bu simanlarda içerdikleri aminlerin ağız ortamında kimyasal değişikliğe uğraması ile amin renklenmesi görülür. Diğer dezavantajları; polimerizasyon büzülmesi, çalışma sürelerinin kısa oluşu, karıştırma sırasında hava ile temas ettiğinden oksijenin polimerizasyonu engellemesidir. ${ }^{2-4}$ Metal desteksiz kuron ve köprüler, metal veya seramik inley ve onley restorasyonları, adeziv köprüler, endodontik post-kor uygulamaları, ışık penetrasyonuna izin vermeyen kor yapısına sahip metal destekli kuronlar ve implant üstü uygulamalarda kullanılabilirler.

\section{b) Iışık ile polimerize olan adeziv rezin simanlar (light-cure)}

İlk bulunduğu yıllarda U.V. Işıkla polimerize edilen tek pat halindeki bu tür simanlar için günümüzde görünür ışık kullanılmaktadır. ${ }^{3}$ Komponentler tüp içinde birlikte olmalarına rağmen, ışık uygulanmadıkça polimerizasyon reaksiyonu başlamaz. ${ }^{6} \mathrm{Bu}$ simanlar, kimyasal ya da dual sertleşen bazı simanlar gibi zamanla renk değiş̧imi göstermezler. Çalışma süreleri, kuronun yerleştirilmesi ve taşan simanın temizlenmesi için uygundur. Farklı opazite ve renk seçeneklerine sahip olmaları estetik başarıyı arttırmıştır. ${ }^{3}$ Akgüngör ve ark.'nın ${ }^{21}$ çalışmasında lityum disilikat bazlı seramiklerde yapışma dayanıklılı̆ının seramik inceliği ve simanın polimerizasyon tipi ile bağlantısı incelenmiştir. Light-cure ve dual-cure simanlar arasında anlamlı farklılık bulunmamıştır. Görünür ışığın penetrasyonuna tamamen izin veren, kalınlığı 1,5-2 mm. den az olan ve tranlusent yapıdaki seramik ve kompozit laminate veneerlerin yapıştırılmasında kullanılırlar. ${ }^{17}$

\section{c) Kimyasal + Işık ile polimerize olan adeziv rezin simanlar (dual-cure)}

İki pat şeklinde bulunurlar. Dual sertleşen simanın ana madde kısmında kamforkinon gibi ışığa hassas polimerizasyon sistemleri, katalizör kısmında ise kimyasal polimerizasyon sistemleri vardır. Çevre dokuların veya alttaki diş dokusunun rengini yansıtacak (bukalemun etkisi), restorasyonun rengiyle uyum sağlayacak şekilde genellikle translusent yapıdadırlar. Dual rezin simanların kimyasal aktivasyonlarının etkinliği yetersiz olduğundan, uygun ışık aktivasyonu materyalin tamamen polimerize olması için çok önemlidir. Işıkla veya dual olarak polimerize olan sistemlerde ışık, restorasyonun her yüzeyinden yaklaşık olarak 60 sn. verilmelidir. Maksimum sertliğe genellikle polimerizasyon dan 10 dak. sonra ulaşılır. Bu tip simanlar restorasyonun bir miktar ışık penetrasyonuna izin verecek kadar translusent olduğu, ancak sadece ışık ile polimerizasyonun tamamen sağlanamayacağı kalınlıktaki (1, 5-2 mm. den fazla olan) restorasyonlarda kullanılır. 5,16

Son yıllarda, bonding sistemlerinin gösterdikleri yüksek bağlanma dayanımı ve sızdırmazlık özelliklerine rağmen, geleneksel rezin simanların hassas teknik gerektirmeleri ve uygulama basamaklarının fazlalığı nedeniyle, "self-adeziv rezin simanlar" kullanıma sunulmuştur. Bu simanlar diş üzerinde herhangi bir ön uygulama gerektirmeksizin doğrudan uygulanmaktadır. Adezyon; polimerizasyonla beraber simanın asidik monomer grupları ve hidroksiapatit arasındaki mikromekanik retansiyon ve kimyasal etkileşime bağlı olarak oluşur. ${ }^{19}$ Self-adeziv rezin simanlarda mikrosızıntı ve sitotoksisite ile ilgili literatürde farklı görüşler sunulmaktadır. Schwap ve $\mathrm{ark}^{2}{ }^{22}$ geleneksel dual-cure simanların sitotoksisite açısından self-adesiv simanlara üstünlük gösterdiğini, bondingin toksisiteyi azalttığını rapor etmişlerdir. Simanların toksik değerlerini düşükten yükseğe doğru; Nexus II (Kerr), Variolink II (Ivoc lar), Relyx Unicem (3M ESPE), Panavia 21 (Kuraray), Fujicem (GC), Maxcem (Kerr) şeklinde tespit etmişlerdir.

\section{Adeziv rezin simanlarda yüzey hazırlıkları Rezin - Mine Bağlantısı}

Minenin asitlenmesinde; \% 30-40'ık ortofosforik asit uygulaması mine yüzeyinden $10 \mu \mathrm{m}$

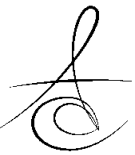


kalınlığında bir tabakayı uzaklaştırır ve demineralize bölgeler meydana getirir. Mine ve dentinin birlikte pürüzlendirildiği adeziv sistemlerde (total etch) aynı anda asit uygulanarak pürüzlendirme işlemi tek aşamalı olarak gerçekleştirilmiş olur. Yeterli bir pürüzlendirme için önerilen süre 15-30 sn. dir. Asit uygulama süresini uzatmak, çözünmüş kalsiyum ve fosfat iyonlarının birleşerek kristal formasyonuna ve yüzey düzensizliklerinin azalmasına neden olarak bağlanmayı olumsuz etkiler. Rezin simanlar, visköz oldukları için asitle pürüzlendirilmiş yüzeylerde oluşan mikroskobik girinti ve çıkıntılara penetre olamadıklarından, bondinglerle birlikte kullanırlar. Bonding sistemleri, pürüzlü yüzeyleri ıslatarak mine prizmalarının çözünmesi ile oluşan boşluklara uzanır ve mine içinde "rezin tag" adı verilen rezin uzantıları oluştururlar. Böylece mikromekanik bağlanma meydana gelir. Son yıllarda Er:YAG ve Er,Cr:YSGG lazerler kullanılarak mine ve dentin yüzeyinde pürüzlendirme işlemlerinin, çeşitli asitlerle yapılan pürüzlendirmeyle karşılaştırıldığı ve bunun rezin simanların bağlanma gücüne etkisini rapor eden pek çok araştırma bulunmaktadır. ${ }^{23,24}$

\section{Rezin - Dentin Bağlantısı}

Dentin bonding sistemler, iki adeziv mekanizmayla fonksiyon görürler. Bunlardan birincisi rezin materyalinin dentin tübülleri içinde rezin uzantıları meydana getirerek mikromekanik bir bağlantı oluşturmalarıdır. İkinci bağlanma mekanizması ise rezin ve dentin elemanlarının karışımından meydana gelen hibrit tabakası oluşumudur. Frez veya kesici aletlerle dentin kesildikten veya prepare edildikten sonra dentin yüzeyinde hidroksiapatit kristalleri, denatüre olmuş kollajen, kan, tükürük ve bakteriden oluşan 1-7 $\mu \mathrm{m}$ kalınlığında smear tabakası oluşur ve altındaki dentin yüzeyine gevşekçe tutunur. Adeziv bağlanmada etkili olan bu tabakanın uzaklaştırıması ya da bağlantıya dahil edilmesi ile ilgili olarak farklı görüşler rapor edilmiştir. ${ }^{25}$

\section{Rezin - Metal Bağlantısı}

Metal yüzeyler ile rezin siman arasındaki bağlantı mikromekanik veya kimyasal olarak iki şekilde sağlanır. Mikromekanik bağlantı; nikel veya kobalt esaslı kıymetsiz alaşımlar için endikedir. Altın ve paladyum içerikli kıymetli alaşımlar bu yöntemle pürüzlendirilemezler. Elektrolitik pürüzlendirme, asit ile pürüzlendirme ve kumlama olmak üzere 3 şekilde yapıır. Kimyasal bağlantıda ise metal yüzeyi, silikat veya kalay ile kaplanarak (silicoater) silanların bağlanabildiği bir yüzey oluşturulur. Daha sonra bu silikat tabakası üzerine silan sürülerek rezin simanla kimyasal bağlantı sağlanır. ${ }^{26}$

\section{Rezin - Seramik Bağlantısı}

Rezinin sıkı bir şekilde seramik yüzeye yapışması, mikromekanik bir yüzey kilitlenmesine ve seramik yüzeyin aktivasyonu ile kimyasal bağlantı sağlanabilmesine bağlıdır. ${ }^{27}$ Yapılan çalışmalar, adeziv hataların en çok rezin-seramik arasında görüldüğünü göstermiştir. 27,28

Asitle pürüzlendirme: Feldspatik ve cam seramikler gibi klasik porselenlere rezin simanın bağlantısı konusunda gerçek bir mikroretansiyon sağlanır. Hidroflorik asit, seramiğin cam matriksini çözerek lösit kristalleri çevresinde mikro andırkatlar oluşturur. Rezin siman bu boşlukları doldurarak güçlü bir mikromekanik bağlantı sağlar. ${ }^{29} \mathrm{Bu}$ yöntem, İnceram, Procera gibi kristalin oranı yüksek seramiklerde tutucu bir yüzey oluşturmakta yetersizken, zirkonyum oksit seramiklerde ise hiçbir etkisi yoktur. ${ }^{27}$

- Aliminyum oksitle kumlama: Bu yöntemde oksitler ve yağsı materyaller porselen yüzeyinden uzaklaştırılarak rezin ile arasındaki tutuculuk arttırılır. Yapılan araştırmalarda; $50 \mu \mathrm{m}$ veya $110 \mu \mathrm{m}$ aliminyum oksitin, 2,5 veya 2,8 bar basınç altında yaklaşık 10 $\mathrm{mm}$. mesafeden uygulanması gerektiği rapor edilmiştir. $^{30,31}$ Phark ve ark, ${ }^{32}$ zirkonyum seramiklerin yapışmasını uzun dönemde in-vitro olarak değerlendirmişler, kumlamanın gerekliliğini desteklemişlerdir.

- Silan uygulaması: Kimyasal bağlantıyı sağlayan silan, kovalent ve hidrojen bağları oluşturarak seramik yüzeylere çok iyi bağlanan bir moleküldür. Seramik yüzeyine asit uygulandıktan sonra silan solusyonu uygulanır ve çözücüsü buharlaşarak uzaklaştıktan sonra rezin siman ile yapıştırılır. Silan; nem kontaminasyonuna çok hassastır ve raf ömrü çok kısadır. Silika esaslı seramiklerde yüzeye silan uygulanması rezin simanın kimyasal olarak seramik yüzeyine bağlanmasını arttırır, ${ }^{33}$ cam infiltre alüminyum oksit seramiklerde kimyasal bir bağlantı oluşturmaz fakat kumlama sonrası yüzeyin ıslatılmasına yardımcı olur. ${ }^{34}$

Tribokimyasal silika kaplama: Bu işlem, alüminyum oksit ve zirkonyum esaslı tam seramiklerde önerilmektedir. Rocatec sistemi (3M ESPE) bu konuda etkili ve kullanımı kolay bir sistemdir. İki aşamalı kumlama ve silan (ESPE-Sil) uygulanması şeklindedir. ${ }^{35}$ Blatz ve ark.' nın ${ }^{27}$ çalışmasında, yoğun sinterlenmiş zirkonyum oksit seramik yüzeyinin yapışma 
dayanıklıı̆ında en iyi değerler; kumlama ile tribokimyasal silika yönteminde bulunmuştur.

\section{SONUÇ}

Sabit protetik uygulamalarda simantasyon önemli bir klinik aşamadır. Adeziv dişhekimliğindeki son gelişmelerle adeziv rezin simanların kullanım alanı artmıştır. Diş sert dokularına ve protetik materyallere iyi derecede bağlanımlarıyla adeziv rezin simanlarla simantasyonda yüksek başarı elde edilmektedir. Son yıllarda, yüksek dayanıklııı, ağız ortamında düşük çözünürlük ve renk uyumundaki üstünlük gibi diğer avantajları, yeni araştırmalarla geliştirilerek klinik uygulamalarda başarı arttırılmaktadır.

\section{KAYNAKLAR}

1. Lad PP, Kamath M, Tarale K, Kusugal PB. Practical clinical considerations of luting cements: A review. J Int Oral Health 2014;6:116-20.

2. Van Landuyt KL, Snauwaert J, De Munck J, Peumans M, Yoshida Y, Poitevin A, Coutinho E, Suzuki K, Lambrechts $P$, Van Meerbeek B. Systematic review of the chemical composition of contemporary dental adhesives. Biomaterials 2007;28:3757-85.

3. Silva e Souza MH, Carneiro KG, Lobato MF, Silva e Souza Pde A, de Goes MF. Adhesive systems: important aspects related to their composition and clinical use. J Appl Oral Sci 2010;18:207-14.

4. Roberson TM, Heymann HO, Swift EJ. Sturdevant's Art and Science of Operative Dentistry. 5 ed. Missouri; Mosby: 2006. Chapter 4.

5. Manso AP, Silva NR, Bonfante EA, Pegoraro TA, Dias RA, Carvalho RM. Cements and adhesives for all-ceramic restorations. Dent Clin North Am 2011;27:321-6.

6. Zaimoğlu A, Can G. Sabit Protezler. 1. baskı. Ankara; A.Ü. Basımevi:2004.p.255-282.

7. Köroğlu A, Ekren $O$, Kurtoğlu C. Conventional and adhesive dental luting agents; a literature review. J Dent Fac Atatürk Uni 2012;22:205-16.

8. Carvalho RM, Manso AP, Geraldeli S, Tay FR, Pashley DH. Durability of bonds and clinical success of adhesive restorations. Dent Mater 2012;28:72-86.
9. Kugel G, Ferrari M. The science of bonding: from first to sixth generation. J Am Dent Assoc 2000;131:20-5.

10. Öztürk N, Aykent F. Dentin bonding ajanlar ve simantasyon. Cumhuriyet Dent J 2001;4:128-31.

11. Imai $H$, Koizumi $H$, Shimoe $S$, Hirata $I$, Matsumura $\mathrm{H}$, Nikawa $\mathrm{H}$. Effect of thione primers on adhesive bonding between an indirect composite material and $\mathrm{Ag}-\mathrm{Pd}-\mathrm{Cu}-\mathrm{Au}$ alloy. Dent Mater J 2014;33:681-8.

12. Piemjai $M$, Arksornnukit M. Compressive fracture resistance of porcelain laminates bonded to enamel or dentin with four adhesive systems. J Prosthodont 2007; 16:457-64.

13. Craig RG, Powers JM, Wataha JC. Dental materials, properties and manipulation. 8 ed. Missouri; Mosby:2004.p.41-51.

14. Anusavice KJ. Phillip's science of dental materials. 11 ed. Missouri; Saunders:2003.p.32568.

15. Bağlar S, Bayraktar Y, Ercan E, Mutluay AT, Şengün $A$. The challenge of MDP monomer containing adhesive systems: Comparison of shear bond strength. J Dent Fac Atatürk Uni 2015;25:21-8.

16. Ferracane JL, Stansbury JW, Burke FJ. Selfadhesive resin cements-chemistry, properties and clinical considerations. J Oral Rehabil 2011;38:295-314.

17. Van Landuyt KL, Nawrot $T$, Geebelen B, De Munck J, Snauwaert J, Yoshihara K, Scheers H, Godderis L, Hoet P, Van Meerbeek B. How much do resin-based dental materials release? A metaanalytical approach. Dent Mater 2011;27:723-47.

18. Makkar S, Malhotra N. Self-adhesive resin cements: a new perspective in luting technology. Dent Update 2013;40:758-60.

19. Regalla RR, Jadav C, Babu DA, Sriram RR, Sriram SK, Kattimani VS. Evaluation and comparison of quantity and pattern of flouride release from orthodontic adhesives: an in vitro study. J Contemp Dent Pract 2014;15:99-102.

20. Radovic I, Monticelli F, Goracci C, Vulicevic ZR, Ferrari M. Self-adhesive resin cements: a literature review. J Adhes Dent 2008;10:251-8.

21. Akgüngör $G, A k k a y a n ~ B$, Gaucher $H$. Influence of ceramic thickness and polymerization mode of a resin luting agent on early bond strength and 
durability with a lithium disilicate-based ceramic system. J Prosthet Dent 2005;94:234-41.

22. Schwap M, Franz A, König F, Bristela M, Lucas T, Piehslinger E, Watts DC, Schedle A. Cytotoxicity of four categories of dental cements. Dent Mater 2009;25:360-8.

23. Lima DM, Tonetto MR, Mendonca AA, Elossais AA, Saad JR, de Andrade MF, Pinto SC, Bandeca $M C$. Human dental enamel and dentin structural effects after Er:YAG laser irradiation. J Contemp Dent Pract 2014;15:283-7.

24. Lin $Y$, Song $X$, Chen $Y$, Zhu Q, Zhang W. Effect of Er:YAG laser irradiation on bonding property of zirconia ceramics to resin cement. Photomed Laser Surg 2013;31:619-25.

25. Mine A, De Munck J, Cardoso MV, Van Landuyt $K L$, Poitevin $A$, Van Ende $A$, Matsumoto $M$, Yoshida $Y$, Kuboki T, Yatani $H$, Van Meerbeek B. Dentin-smear remains at self-etch adhesive interface. Dent Mater 2014;30:1147-53.

26. Hernandez AI, Roongruangphol T, Katsube N, Seghi RR. Residual interface tensile strength of ceramic bonded to dentin after cyclic loading and aging. J Prosthet Dent 2008;99:209-17.

27. Blatz MB, Sadan A, Kern M. Resin-ceramic bonding: a review of literature. J Prosthet Dent 2003;89:268-74.

28. Zorzin J, Belli R, Wagner A, Petschelt A, Lohbauer $U$. Self-adhesive resin cements: adhesive performance to indirect restorative ceramics. J Adhes Dent 2014;16:541-6.

29. Kim JH, Chae S, Lee Y, Han GJ, Cho BH. Comparison of shear test methods for evaluating the bond strength of resin cement to zirconia ceramic. Acta Odontol Scand 2014;72:745-52.

30. Piwowarczyk A, Lauer HC, Sorensen JA. In vitro shear bond strength of cementing agents to fixed prosthodontic restorative materials. J Prosthet Dent 2004;92:265-73.

31. Barragan G, Chasqueira F, Arantes-Oliveira S, Portugal J. Ceramic repair: influence of chemical and mechanica surface conditioning on adhesion to zirconia. Oral Health Dent Manag 2014;13:155-8.

32. Phark JH, Duarte $S$, Blatz $M$, Sadan A. An in vitro evaluation of the long term resin bond to a new densely sintered high-purity zirconium-oxide ceramic surface. J Prosthet Dent 2009;101:29-
38.

33. Kumbuloglu O, Lassila LVJ, User A, Toksavul S, Vallittu PK. Shear bond strength of composite resin cements to lithium disilicate ceramics. J Oral Rehabil 2000;32: 128-133.

34. Elsaka SE. Bond strength of novel CAD/CAM restorative materials to self-adhesive resin cement: the effect of surface treatments. J Adhes Dent 2014;16:531-40.

35. Özcan M, Vallittu PK. Effect of surface conditioning methods on the bond strength of luting cement to ceramics. Dent Mater 2003;19:725-31.

\section{Yazışma Adresi}

Dr. Sibel Dikicier

Çorlu Asker Hastanesi,

Diş Servisi, 59186,

Tekirdağ, Türkiye

Tel: +902826511051

Fax: +902826521846

e-mail: dtsibel@hotmail.com 